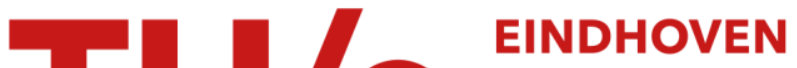 UNIVERSITY OF TECHNOLOGY
}

\section{Platinum particle size effect during the catalytic oxidative dehydrogenation of aqueous ethanol}

Citation for published version (APA):

Tillaart, van den, J. A. A., Kuster, B. F. M., \& Marin, G. B. M. M. (1996). Platinum particle size effect during the catalytic oxidative dehydrogenation of aqueous ethanol. Catalysis Letters, 36(1-2), 31-36.

https://doi.org/10.1007/BF00807202

DOI:

10.1007/BF00807202

Document status and date:

Published: 01/01/1996

\section{Document Version:}

Publisher's PDF, also known as Version of Record (includes final page, issue and volume numbers)

\section{Please check the document version of this publication:}

-A submitted manuscript is the version of the article upon submission and before peer-review. There can be important differences between the submitted version and the official published version of record. People interested in the research are advised to contact the author for the final version of the publication, or visit the $\mathrm{DOI}$ to the publisher's website.

- The final author version and the galley proof are versions of the publication after peer review.

- The final published version features the final layout of the paper including the volume, issue and page numbers.

Link to publication

\section{General rights}

Copyright and moral rights for the publications made accessible in the public portal are retained by the authors and/or other copyright owners and it is a condition of accessing publications that users recognise and abide by the legal requirements associated with these rights.

- Users may download and print one copy of any publication from the public portal for the purpose of private study or research.

- You may not further distribute the material or use it for any profit-making activity or commercial gain

- You may freely distribute the URL identifying the publication in the public portal.

If the publication is distributed under the terms of Article $25 \mathrm{fa}$ of the Dutch Copyright Act, indicated by the "Taverne" license above, please follow below link for the End User Agreement:

www.tue.nl/taverne

Take down policy

If you believe that this document breaches copyright please contact us at:

openaccess@tue.nl

providing details and we will investigate your claim. 


\title{
Platinum particle size effect on the oxidative dehydrogenation of aqueous ethanol
}

\author{
J.A.A. van den Tillaart, B.F.M. Kuster and G.B. Marin 1 \\ Laboratorium voor Chemische Technologie, Schuit Institute of Catalysis, Eindhoven University of Technology, \\ PO Box 513, $5600 \mathrm{MB}$ Eindhoven, The Netherlands
}

Received 21 October 1994; accepted 6 September 1995

\begin{abstract}
The effect of the platinum particle size was investigated for the catalytic oxidative dehydrogenation of aqueous ethanol to ethanal at a temperature of $303 \mathrm{~K}$, an ethanol concentration of $260 \mathrm{~mol} \mathrm{~m}^{-3}$, a partial oxygen pressure $60 \mathrm{kPa}$, a pH of 9 , and an ethanal and ethanoate concentration of $20 \mathrm{~mol} \mathrm{~m}^{-3}$. A particle size effect on the turnover frequency was observed but only for particle sizes smaller than $2 \mathrm{~nm}$. Hence, the reaction shows a limited structure sensitivity.
\end{abstract}

Keywords: ethanol; kinetics; oxidation; oxydehydrogenation; platinum; structure sensitivity

\section{Introduction}

Maximization of the rate of a metal catalyzed reaction per unit mass of noble metal, i.e. of the so-called specific reaction rate, cannot always be achieved simply by maximization of the surface area per unit mass of noble metal, i.e. by minimization of the particle size of the noble metal. Studies on many reactions show that the reaction rate per unit catalyst surface area can depend on the particle size, hence minimization of the particle size will not automatically yield maximization of the rate per unit mass. Reaction rates per unit surface area of the active phase are often expressed as turnover frequencies, TOF, i.e. as rates per surface atom of the active phase. Boudart called reactions with a clear dependence of this TOF on the particle size "demanding" or "structure-sensitive" [1,2]. Reactions which do not exhibit such dependence were called "facile" or "structureinsensitive".

Che and Bennet [3] reviewed recently the effect of particle size of supported metals on the rate of catalytic reactions with omission of the work in the field of electrocatalysis. Possible explanations for the particle size effect of metals can be mainly divided in electronic effects and geometric effects.

Electronic effects arise from the fact that when metal particles become smaller the electronic character will change from typical for a bulk metal to typical for a single metal atom. The electronic character of a metal cluster influences physical and chemical properties such as electrical conductivity, ionization potential, polarizability, binding energy, Gibbs energy, entropy and so on [4]. Electronic effects will start to occur at a particle size at which the difference between two subsequent energy levels will become appreciable with respect to the ther-

1 To whom correspondence should be addressed. mal energy $k_{\mathrm{B}} T$ ( $k_{\mathrm{B}}$ is the Boltzmann constant $\left.=0.3807 \times 10^{-23} \mathrm{~J} \mathrm{~K}^{-1}\right)$. For platinum particles this amounts to a particle size of about $2 \mathrm{~nm}$ [5]. Such a particle consists of approximately 200 atoms.

Geometric effects arise from the fact that the active site for the reaction can consist of a special type of surface atom or an ensemble of surface atoms [6] rather than a single surface atom. Van Hardeveld and Hartog $[7,8]$ calculated for various shapes of particles the fraction of different types of sites with respect to the total amount of surface atoms. The fraction of face atoms on fcc octahedra for instance decreases sharply at a particle size of about $2 \mathrm{~nm}$. The fraction of so-called B5 sites on fcc octahedra goes through a maximum at a particle size of about $2.5 \mathrm{~nm}$. Che and Bennet [3] concluded from calculations that when the active site for a reaction consists of an ensemble of several atoms the structure sensitivity of the reaction should extend to particles considerably larger than $5 \mathrm{~nm}$. The larger the ensemble required the larger the particle size to which sensitivity persists. Hence, this kind of behavior was called extended structure sensitivity. When the active site consists of a certain type of surface atom rather than of an ensemble, the structure sensitivity is limited to particles smaller than $5 \mathrm{~nm}$. This is therefore called limited structure sensitivity. Che and Bennet [3] also distinguished between antiand sympathetic structure sensitivity. The former corresponds to a turnover frequency which increases with increasing particle diameter.

Peuckert et al. [9] showed that the turnover frequency of the electrochemical dioxygen reduction over platinum on carbon catalysts in $0.5 \mathrm{M} \mathrm{H}_{2} \mathrm{SO}_{4}$ at $298 \mathrm{~K}$ decreased sharply at particle sizes smaller than 2 to $4 \mathrm{~nm}$. A constant turnover frequency was observed on particles larger than $4 \mathrm{~nm}$. It was also shown by cyclovoltammetry that the oxide reduction was shifted to lower potentials as the particle size decreased. This was ascribed to an 
increased heat of chemisorption of oxygen on smaller particles.

The latter is in agreement with the gas phase work of Briot et al. [10], who found for a platinum on alumina catalyst that the turnover frequency of the oxidation of methane by dioxygen was much higher for aged catalysts, with platinum particles of approximately $12 \mathrm{~nm}$, than for fresh catalysts with a particle size of approximately $2 \mathrm{~nm}$. Microcalorimetric measurements of the oxygen chemisorption showed a decrease in the heat of chemisorption of oxygen with increasing particle size from $280 \mathrm{~kJ} \mathrm{~mol}^{-1}$, for the particles of $2 \mathrm{~nm}$, to $250 \mathrm{~kJ}$ $\mathrm{mol}^{-1}$, for the particles of $12 \mathrm{~nm}$. This explains the increased reactivity of the adsorbed oxygen with increasing particle size.

Schuurman et al. [11] also explained an observed antipathetic particle size effect on the oxidation of methyl $\alpha$-D-glucoside over a platinum on graphite catalyst as a result of the stronger oxygen platinum bond on small particles.

This paper reports on the effect of platinum particle size on the oxidative dehydrogenation of aqueous ethanol.

\section{Experimental}

Experimental difficulties in determining the particle size effect on the turnover frequency for metal catalysts could arise from various causes [3]. Changes in metal support interaction (strong metal support interaction, SMSI), incomplete reduction of the metal, particle structure, deactivation and metal reconstruction upon adsorption with the particle size can obscure the real particle size effect on the TOF for a certain reaction. To obtain good data on the effect of the particle size, or the fraction exposed atoms on the turnover frequency for a certain reaction the metal particles should thus be approximately monodisperse, fully reduced, unpoisoned and show little interaction with the support.

\subsection{Catalyst preparation}

A highly dispersed platinum on graphite catalyst was prepared following a method described by Richard and Gallezot [12]. High surface area graphite from Johnson Matthey (CH10213) was first activated by partial combustion of batches of $8 \mathrm{~g}$ in an air flow of $300 \mathrm{Nml} \mathrm{min} \mathrm{m}^{-1}$ at $773 \mathrm{~K}$ for $5 \mathrm{~h}$. Under these conditions $25 \mathrm{wt} \%$ of the graphite was burned off. The amount of graphite burned off was not stoichiometrically limited by the total amount of air fed as this was sufficient to burn the graphite completely to $\mathrm{CO}_{2}$. Subsequently the graphite was suspended at ambient temperature for $24 \mathrm{~h}$ in a solution of concentrated sodium hypochlorite $(13 \mathrm{wt} \%$ in active chlorine, Janssen p.a.). After this wet activation step the graphite was separated from the solution by filtration on a Millipore filter (HV $0.45 \mu$ ), carefully rinsed with distilled water and dried in a vacuum oven at $373 \mathrm{~K}$. These two activation steps create oxygen containing surface groups at the edges of the carbon layers [12]. These groups will later act as anchoring sites for the platinum complex. A high concentration of such sites is necessary to obtain a highly dispersed platinum catalyst [13], i.e. to obtain a catalyst with a high fraction of platinum atoms exposed at the surface.

Platinum was introduced on the activated support by a competitive cation exchange [3] of platinumtetramine and ammonium ions with the anchoring sites of on the support to obtain a more uniform platinum distribution throughout the whole support. As Richard and Gallezot [12] achieved a maximum platinum uptake in a suspension with $20 \mathrm{wt} \%$ platinum with respect to the amount of graphite, a calculated amount of a platinumtetramine hydroxide solution $(100 \mathrm{~g} 8 \mathrm{wt} \%$ in platinum, Johnson Matthey or $50 \mathrm{~g} 16 \mathrm{wt} \%$ in platinum, Degussa) was added dropwise to a suspension of $40 \mathrm{~g}$ graphite in $800 \mathrm{ml}$ $1 \mathrm{M}$ ammonia (Merck p.a.) and stirred at ambient temperature for $24 \mathrm{~h}$. The catalyst was separated from the suspension by filtration on a Millipore filter (HV $0.45 \mu)$, washed with distilled water and dried in a vacuum oven at $373 \mathrm{~K}$. The dried catalyst was reduced in flowing hydrogen at 473 or $573 \mathrm{~K}$ for $2 \mathrm{~h}$ and stored exposed to air before use.

\subsection{Catalyst sintering}

To obtain catalyst samples with different platinum particle sizes but which are similar with respect to platinum content and support, samples of a freshly prepared catalyst batch were treated for 2 to $4 \mathrm{~h}$ at temperatures ranging from 473 to $773 \mathrm{~K}$ in flowing air as indicated in table 1 . The samples were subsequently reduced for $2 \mathrm{~h}$ in flowing hydrogen at $473 \mathrm{~K}$. All samples were stored before use exposed to ambient air.

\subsection{Catalyst characterization}

\subsubsection{Platinum content}

The platinum content of the catalyst was determined by UV/VIS spectrophotometry at $403 \mathrm{~nm}$ of a stable yellow $\mathrm{Sn}-\mathrm{Pt}$ complex formed by platinum ions and $\mathrm{SnCl}_{2}$ in the presence of excess chlorine ions [14-16].The plati-

Table 1

Preparation conditions for the catalyst samples referred to in this work

\begin{tabular}{llll}
\hline Catalyst & Reduction & Treatment & Reduction \\
\hline D0 & $2 \mathrm{~h} \mathrm{H}_{2} 473 \mathrm{~K}$ & - & - \\
D1 & $"$ & 2h air $473 \mathrm{~K}$ & $2 \mathrm{~h} \mathrm{H} \mathrm{H}_{2} 473 \mathrm{~K}$ \\
D2 & $"$ & $4 \mathrm{~h}$ air $523 \mathrm{~K}$ & $"$ \\
D3 & $"$ & $4 \mathrm{~h}$ air $573 \mathrm{~K}$ & $"$ \\
D4 & $"$ & $4 \mathrm{~h}$ air $673 \mathrm{~K}$ & $"$ \\
\hline
\end{tabular}


num is released and dissolved from the support by boiling the catalyst in aqua regia.

\subsubsection{Platinum particle size distribution}

Transmission electron microscopy micrographs were obtained on a JEOL 2000 CX microscope with an accelerating potential of $200 \mathrm{kV}$ at a microscope magnification of $5 \times 10^{5}$. The resolution of this microscope was better than $1 \mathrm{~nm}$ at the conditions used. The final magnification on the micrographs was $2 \times 10^{6}$.

The catalyst samples were ultrasonically dispersed in water, brought, suspended in water, onto coated copper grids and finally dried by exposure to air. Different types of grids were tried but only self prepared grids and perforated "lacey" grids supplied by Biorad gave good results.

The platinum particle size distribution was obtained from the micrographs by using a computer equipped with a camera and image analysis software (TIM 3.35, TEA DIFA measuring systems). Sections of the micrograph were digitized and stored in the computer. Direct analysis of the particles on these digitized images was not possible because of the non-uniform background due to the non-uniform thickness of the graphite support. Therefore a defocused digitized image of the same section was subtracted from the original image. The defocused image contains only information on the average gray level distribution and so the particles become visible as dark spots on a more uniform light background. After noise filtering and contrast enhancement, the particles which were clearly the same in shape and size on both the original micrograph and on the final computer image were selected. The software subsequently determined the surface area of these selected particles. The equivalent platinum particle diameter, $d$ (in $\mathrm{m}$ ), was defined as the diameter of a circle with the same surface area as the platinum particle.

The surface area averaged platinum particle diameter, $d_{\mathrm{s}}$ (in $\mathrm{m}$ ), was determined from the distribution according to Lemaître et al. [17]:

$d_{s}=\frac{\sum n_{i} d_{i}^{3}}{\sum n_{i} d_{i}^{2}}$

where the summation goes over all considered size classes, $i$, with an equivalent diameter $d_{i}$ and a number, $n_{i}$, of counted particles in that class.

The sample standard deviation for the surface area averaged platinum particle size, $s_{\mathrm{s}}$ (in $\mathrm{m}$ ), which contains information about the width of the particle size distribution, assuming a Gaussian distribution, is then defined by:

$s_{\mathrm{s}}=\sqrt{\frac{\sum n_{i} d_{i}^{2}\left(d_{i}-d_{\mathrm{s}}\right)^{2}}{\sum n_{i} d_{i}^{2}}}$.

If sufficient data is present the $95 \%$ confidence interval for the surface averaged diameter is given by: $d_{\mathrm{s}} \pm \frac{1.96 s_{\mathrm{s}}}{\sqrt{n}}$

in which $n$ is the total number of counted particles.

\subsubsection{Accessible platinum surface atoms}

The fraction of platinum atoms exposed, FE, was determined by $\mathrm{CO}$ pulse chemisorption as this technique quantifies the amount of platinum surface atoms accessible for chemisorption. The catalyst was dried at $333 \mathrm{~K}$ in vacuum prior to the chemisorption measurement. An amount of 40 to $60 \mathrm{mg}$ of catalyst was then reduced in situ during $1 \mathrm{~h}$ in flowing hydrogen at $373 \mathrm{~K}$. After cooling down to $273 \mathrm{~K}$ the chemisorption of pulses of $\mathrm{CO}$ in helium carrier gas was determined. The fraction of platinum atoms at the surface was calculated from the total amount of adsorbed $\mathrm{CO}$ and the platinum content of the catalyst assuming a 1:1 adsorption stoichiometry.

\subsection{X-ray absorption spectroscopy}

$\mathrm{X}$-ray absorption measurements were performed at station 9.2 of the SRS at Daresbury (UK) with an electron beam energy of $2 \mathrm{GeV}$ and a stored current varying between 290 and $160 \mathrm{~mA}$. The wiggler was operational at $5.0 \mathrm{~T}$. Data were collected in the transmission mode from 11.37 to $13.43 \mathrm{keV}$ (Pt L LII-edge: $11.564 \mathrm{keV}, \mathrm{Pt}$ $\mathrm{L}_{\mathrm{II}}$-edge: $13.273 \mathrm{keV}$ ) with a $\mathrm{Si}(220)$ monochromator detuned to $50 \%$ of the maximum intensity for harmonic rejection. The ion chambers were filled with gas mixtures optimized to suit the measuring conditions. Energy calibration was monitored using a gold foil or a platinum foil and a third ion chamber, and was set at $11.919 \mathrm{keV}$ at the Au L LII-edge or $11.564 \mathrm{keV}$ for the Pt $\mathrm{L}_{\mathrm{III}}$-edge. The spot size was reduced with the entrance slits to give a spot of $1 \mathrm{~mm}$ height and $10 \mathrm{~mm}$ width. Energy resolution was estimated to be $2.2 \mathrm{eV}$. Samples were scanned eight times to determine the error in the data and to improve the data quality by averaging.

Data analysis was performed with software developed at the Laboratory of Inorganic Chemistry and Catalysis of the Eindhoven University of Technology [18] and follows mainly the procedure described by Sayers and Bunker [19].

\subsection{Kinetic experiments and reaction conditions}

The reactor setup and working procedure as described by van den Tillaart [20] were used to determine the steady state specific disappearance rate of ethanol for the different catalyst samples. The catalyst was treated in situ with hydrogen at $363 \mathrm{~K}$ immediately before reaction. The reaction conditions used for the measurements are given in table 2 . The amount of catalyst was varied depending on the catalyst activity from 180 to $350 \mathrm{mg}$. It was confirmed that the observed specific disappearance rate of ethanol was free of mass transfer lim- 
Table 2

Reaction conditions at which the platinum particle size effect was investigated

\begin{tabular}{ll}
\hline Condition & Value \\
\hline concentration ethanol & $260 \mathrm{~mol} \mathrm{~m}^{-3}$ \\
concentration ethanal & $20 \mathrm{~mol} \mathrm{~m}^{-3}$ \\
concentration ethanoate & $20 \mathrm{~mol} \mathrm{~m}^{-3}$ \\
oxygen partial pressure & $60 \mathrm{kPa}$ \\
$\mathrm{pH}$ & 9 \\
temperature & $303 \mathrm{~K}$ \\
conversion of ethanol & \pm 0.13 \\
& \\
\hline
\end{tabular}

itations at these conditions and hence represented the true intrinsic kinetics. The experiments were replicated several times to obtain an estimate of the experimental error in the reaction rate. Steady state rates generally were obtained after one hour and could be maintained for several hours. For the conditions used no permanent deactivation, like platinum crystallite growth, occurred.

The turnover frequency (TOF, in $\mathrm{s}^{-1}$ ) for the disappearance of ethanol based on platinum surface atoms is given by:

$\mathrm{TOF}=\frac{R_{\mathrm{W}} M_{\mathrm{Pt}}}{w_{\mathrm{Pt}} \mathrm{FE}}$,

where $R_{\mathrm{W}}$ is the specific disappearance rate $(\mathrm{mol} \mathrm{kg}-1$ $\left.\mathrm{s}^{-1}\right), M_{\mathrm{Pt}}$ is the platinum molar mass $\left(\mathrm{kg} \mathrm{mol}^{-1}\right)$, and $w_{\mathrm{Pt}}$ is the platinum weight fraction.

\section{Results and discussion}

\subsection{Catalyst characterization}

The results of the catalyst characterization are summarized in table 3. It is clear from these results that the platinum particle size increases as the sintering temperature was higher. Also the platinum content increases as the sintering temperature was increased indicating that the graphite support was somewhat burned off during sintering. The decrease of the fraction of exposed platinum atoms, $\mathrm{FE}$, as determined by $\mathrm{CO}$ pulse chemisorption, is in agreement with the increase of the particle size. From fig. 1 and table 3 it is clear that the width of the particle size distribution has been increased

Table 3

Summary of platinum particle size analysis results

\begin{tabular}{llllll}
\hline Catalyst & $\begin{array}{l}w_{\mathrm{Pt}} \\
(\mathrm{wt} \%)\end{array}$ & $\begin{array}{l}d_{\mathrm{s}} \\
(\mathrm{nm})\end{array}$ & $\begin{array}{l}s_{\mathrm{s}} \\
(\mathrm{nm})\end{array}$ & $n$ & $\mathrm{FE}$ \\
\hline D0 & $3.56 \pm 0.13$ & $1.46 \pm 0.03$ & 0.34 & 530 & $0.597 \pm 0.005$ \\
D1 & $3.64 \pm 0.06$ & $1.53 \pm 0.04$ & 0.35 & 299 & $0.600 \pm 0.010$ \\
D2 & $3.76 \pm 0.10$ & $1.59 \pm 0.04$ & 0.38 & 322 & $0.580 \pm 0.010$ \\
D3 & $3.81 \pm 0.05$ & $1.85 \pm 0.05$ & 0.42 & 282 & $0.572 \pm 0.003$ \\
D4 & $4.24 \pm 0.08$ & $2.20 \pm 0.07$ & 0.61 & 277 & $0.467 \pm 0.009$ \\
\hline
\end{tabular}
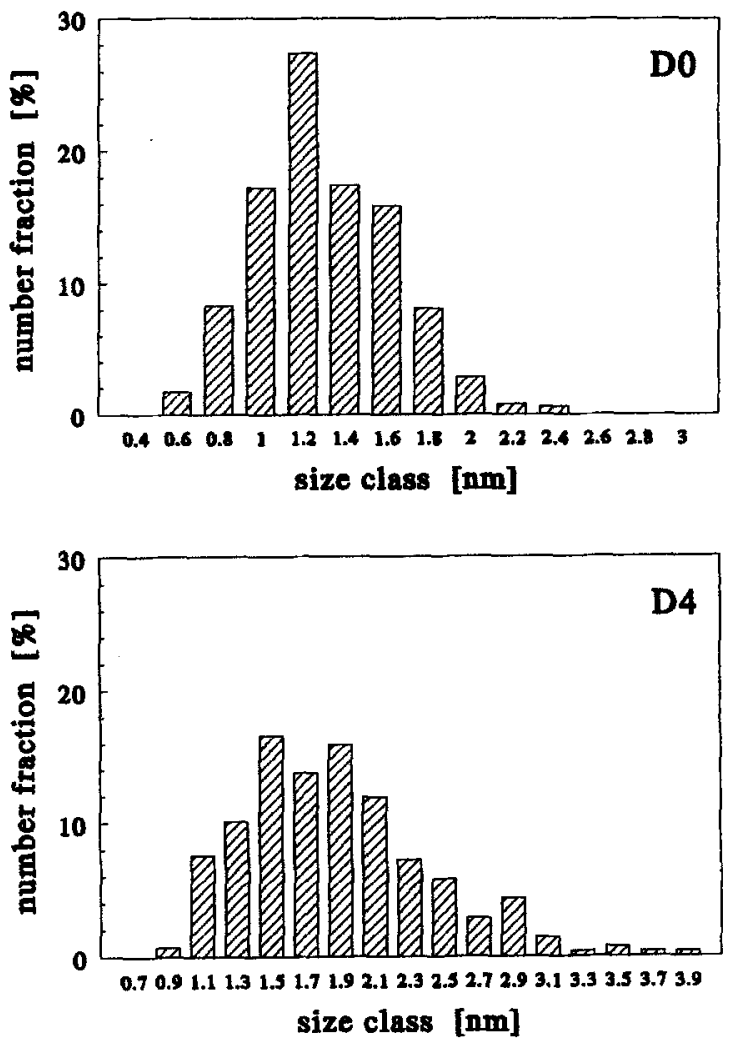

Fig. 1 Platinum particle size distribution of several catalyst samples as determined by TEM micrograph analysis.

slightly by the sintering but that the particles are still monodisperse.

There is some discussion in literature about the crystal structure of small platinum particles. Renouprez et al. [21] concluded from EXAFS measurements that the structure of a Pt/ $\mathrm{SiO}_{2}$ catalyst with platinum particles of $1.8 \mathrm{~nm}$ could be well described with a $5 \%$ contracted fcc structure, whereas a $\mathrm{Pt} /$ zeolite catalyst with platinum particles of $1.1 \mathrm{~nm}$ could be better described by a $7 \%$ contracted icosahedron, which is not a fcc structure. Joyner and Meehan [22] studied EUROPT-1, a $6.3 \mathrm{wt} \% \mathrm{Pt} /$ $\mathrm{SiO}_{2}$ catalyst, and a $2.5 \mathrm{wt} \%$ platinum on carbon catalyst with platinum particles larger than $1.8 \mathrm{~nm}$. They concluded for both catalysts that the fcc structure is maintained even in platinum particles as small as $1.8 \mathrm{~nm}$. Their conclusion is also supported by this work. Fig. 2 shows the corrected Fourier transforms of the EXAFS of a platinum foil, a reduced sample of catalyst D0, and a reduced sample of catalyst D2. It is clear from this figure that even in platinum particles as small as in catalyst D0, with an average platinum particle size of $1.46 \mathrm{~nm}$, the same fcc structure as in the platinum foil is maintained with interatomic distances close to the fec $\mathrm{Pt}-\mathrm{Pt}$ distances in bulk platinum of $2.775 \times 10^{-10}$, $3.934 \times 10^{-10}, 4.806 \times 10^{-10}$ and $5.550 \times 10^{-10} \mathrm{~m}$.

From earlier XAS experiments [23] it was already clear that exposure to ambient air of small reduced platinum particles leads to a strong corrosive oxidation 

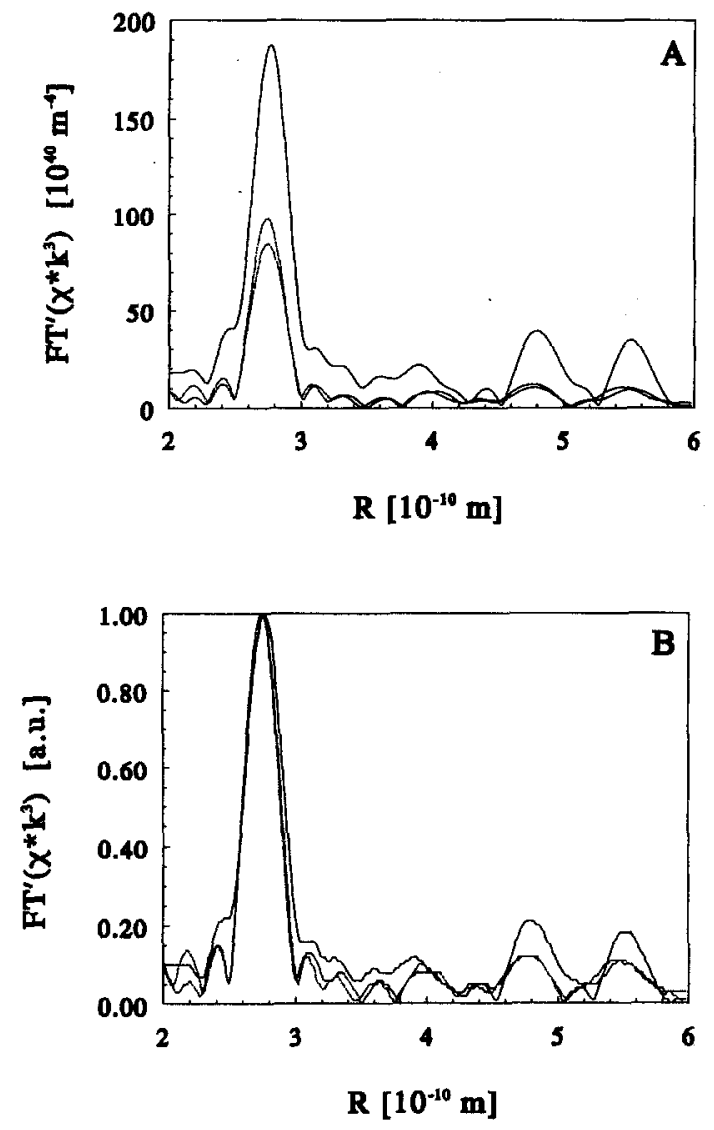

Fig. 2. Fourier transform (A) and scaled Fourier transform (B) of $k^{3}$ weighted X-ray absorption spectra, $k$-range: $\left(3.1-16 \times 10^{10} \mathrm{~m}^{-1}\right.$ and corrected for the Pt-Pt phase-shift and amplitude functions. Full line: platinum foil, dashed line: reduced sample of catalyst $\mathrm{D} 0$, and dotted line: reduced sample of catalyst D2. ( $k$ is the photoelectron wave number, $\chi$ is the normalised modulation of the absorption coefficient.)

resulting in a particle consisting of a shell of $\mathrm{PtO}_{2}$ and a core of metallic platinum. Such an oxidized particle can, however, be reduced easily by reduction at ambient temperatures in hydrogen gas or in hydrogen saturated aqueous solutions. Exposure to oxygen saturated water did not lead to such a strong corrosive oxidation.

Summarizing, it can be said that all the investigated catalyst samples consist of fully reduced platinum particles with an identical crystal structure.

\subsection{Particle size effect}

Fig. 3A shows the specific disappearance rate of ethanol versus the particle diameter. The error bar reflects the instability of the steady-state concentrations as well as the analytical error. This figure shows a maximum in the specific disappearance rate of ethanol at a particle diameter of approximately $2 \mathrm{~nm}$. Fig. 3B shows the turnover frequency of the ethanol disappearance versus the particle diameter. The turnover frequency seems to become constant for particles larger than $2 \mathrm{~nm}$. The turnover frequency decreases on particles smaller than
$2 \mathrm{~nm}$. Following from the definitions of Che and Bennet [3] given in the introduction, fig. 3B indicates a limited antipathetic structure sensitive reaction. The form of the curve is in good agreement with the results of Peuckert et al. [9] for the electrochemical reduction of dioxygen over $\mathrm{Pt} /$ carbon and with the results of Schuurman et al. [11] for the oxidation of methyl $\alpha$-D-glucoside over Pt/ graphite.

According to a kinetic study of the ethanol oxidation on a $\mathrm{Pt} /$ graphite catalyst with a particle diameter of $1.95 \mathrm{~nm}$ [20], the kinetics of this reaction can be described adequately by a relatively simple rate equation based on an irreversible dissociative adsorption of oxygen and an equilibrated reversible dissociative adsorption of ethanol on the same type of sites. These steps are followed by irreversible surface reactions between two adsorbed species towards the reaction products:

$$
\begin{array}{cc}
\mathrm{O}_{2}+2 * \rightarrow 2 \mathrm{O} * & 1 \\
\mathrm{CH}_{3} \mathrm{CH}_{2} \mathrm{OH}+2 * \rightarrow 5 \mathrm{CH}_{3} \mathrm{CH}_{2} \mathrm{O} *+\mathrm{H} * & 2 \\
\mathrm{CH}_{3} \mathrm{CH}_{2} \mathrm{O} *+\mathrm{O} * \rightarrow \mathrm{CH}_{3} \mathrm{CHO}+\mathrm{OH} *+* & 2 \\
\mathrm{H} *+\mathrm{OH} * \rightarrow \mathrm{H}_{2} \mathrm{O}+2 * & 2 \\
\hline 2 \mathrm{CH}_{3} \mathrm{CH}_{2} \mathrm{OH}+\mathrm{O}_{2} \rightarrow 2 \mathrm{CH}_{3} \mathrm{CHO}+2 \mathrm{H}_{2} \mathrm{O} &
\end{array}
$$

The last step in the above sequence can be considered to be potentially much faster than the other irreversible steps. Hence, the global rate of reaction is determined mainly by both the rate coefficient of the chemisorption
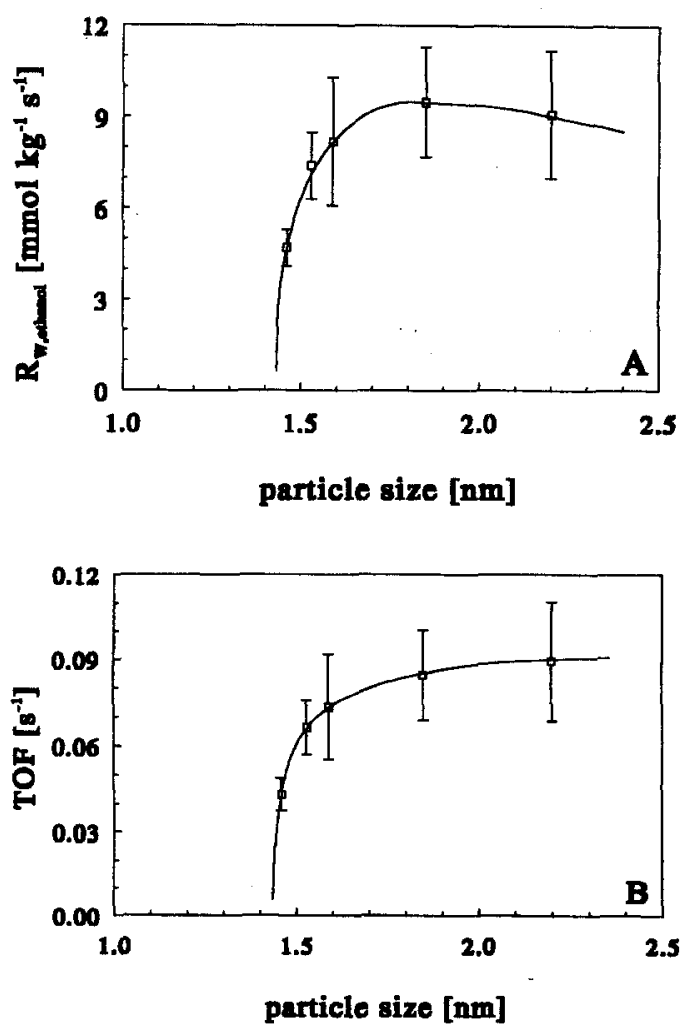

Fig. 3. Specific disappearance rate of ethanol (A) and turnover frequency of ethanol disappearance (B) vs. the surface area averaged platinum particle diameter. Reaction conditions see table 2. 
of oxygen and the rate coefficient of the irreversible surface reaction between the ethoxy species and the oxygen species. These rate coefficients influence the global rate directly and via the degree of coverage in the steady state. Indeed, the surface coverage of oxygen is not the result of an equilibrium between adsorption and desorption, but is rather the result of a balance between the adsorption rate of oxygen and the oxygen consumption rate via the surface reaction. The rate equation and corresponding estimates for the kinetic parameters selected by van den Tillaart et al. [20], allows to calculate that the oxygen coverage on the catalyst sample with a platinum particle size of $1.95 \mathrm{~nm}$ is about 0.34 at the conditions at which the particle size effect has been investigated in the present work.

The increased heat of chemisorption for oxygen with decreasing particle diameter $[9,10]$ results in a decrease of the activation energy for the adsorption according to the relation of Polanyi [24], and hence in an increase of the adsorption rate coefficient.

Similar arguments lead to Sabatier's principle that a reactive intermediate should be stable enough to be formed easily but not too stable in order to decompose easily towards the reaction product [24]. This effect is clearly observed in the so-called "volcano curves": the rate of the global reaction first increases with the binding energy of a key reactant with the catalyst, then reaches a maximum and starts to decrease as the binding energy becomes too high. It is possible to explain the observed increase in the TOF with increasing particle size with a Sabatier type of explanation when the oxygen-platinum bond strength influences both the rate of adsorption of oxygen and of the surface reaction and when the binding energy is higher than the optimal binding energy, i.e. when the oxygen-platinum bond strength is situated on the right-hand side of the "volcano curve". This does, however, not necessarily mean that this bond has to be broken during the surface reaction. It is possible that the stronger bonded oxygen on the smaller platinum particles is less capable of abstracting hydrogen from the adsorbed ethanol species. Apparently this effect is countered only partially by the increased degree of oxygen coverage, resulting from the higher adsorption rate of oxygen, to result in the observed decrease of the turnover frequency with decreasing particle size.

\section{Conclusions}

The oxidation of ethanol with dioxygen over a platinum on graphite catalyst shows a particle size effect on the turnover frequency at particle sizes smaller than $2 \mathrm{~nm}$, corresponding to a limited structure sensitivity. Most probably only a few surface atoms are needed for this reaction. The particle size effect can be explained by the increased strength of the oxygen platinum bond. The stronger bonded oxygen on small platinum particles is less capable of abstracting a hydrogen atom from the adsorbed ethanol species thereby decreasing the rate of reaction at the investigated conditions.

\section{Acknowledgement}

The X-ray absorption spectroscopy measurements have been made possible by a grant from the Netherlands Organization for Scientific Research (NWO).

\section{References}

[1] M. Boudart, A. Aldag, J.E. Benson, N.A. Dougharty and C.C. Harkins, J. Catal. 6(1966) 92.

[2] M. Boudart, Adv. Catal. 20 (1969) 153.

[3] M. Che and C.O. Bennet, Adv. Catal. 36(1989) 55.

[4] H. Muller, C. Opitz and L. Skala, J. Mol. Catal. 54 (1989) 389.

[5] G.C. Bond, Surf. Sci. 156 (1985) 966.

[6] C.O. Bennet and M. Che, J. Catal. 120(1989) 293

[7] R. van Hardeveld and F. Hartog, Surf. Sci. 15(1969) 189.

[8] R. van Hardeveld and F. Hartog, Adv. Catal. 22 (1972) 75.

[9] M. Peuckert, T. Yoneda, R.A. Dalla Betta and M. Boudart, J. Electrochem. Soc.: Electrochem. Sci. Tech. 133 (1986) 944.

[10] P. Briot, A. Auroux, D. Jones and M. Primet, Appl. Catal. 59 (1990) 141.

[11] Y. Schuurman, B.F.M. Kuster, K. van der Wiele and G.B. Marin, Appl. Catal. A 89 (1992) 47.

[12] D. Richard and P. Gallezot, in: Preparation of Catalysts IV, eds. B. Delmon, P. Grange, P.A. Jacobs and G. Poncelet (Elsevier, Amsterdam, 1987)p. 71 .

[13] P. Ehrburger, Adv. Coll. Interf. Sci. 21 (1984) 275.

[14] G.H. Ayres and A.S. Meyer, Anal. Chem. 23 (1951) 299.

[15] G.H. Ayres and A.S. Meyer, J. Am. Chem. Soc. 77 (1955) 2671.

[16] G. Charlot, Les Méthodes de la Chimie Analytique (Masson, Paris, 1961).

[17] J.L. Lemaître, P.G. Menon and F. Delannay, in: Characterization of Heterogeneous Catalysts, Chemical Industries, Vol. 15, ed. F. Delannay (Dekker, New York, 1984) p. 299.

[18] M. Vaarkamp, The Structure and Catalytic Properties of Supported Platinum Catalysts, $\mathrm{PhD}$ Thesis, Eindhoven University of Technology, The Netherlands (1993).

[19] D.E. Sayers and B.A. Bunker, in: X-ray Absorption: Principles, Applications, Techniques of EXAFS, SEXAFS and XANES, eds. D.C. Koningsberger and R. Prins (Wiley, New York, 1988) p. 211

[20] J.A.A. van den Tillaart, B.F.M. Kuster and G.B. Marin, Appl. Catal. A 120 (1994) 127.

[21] A. Renouprez, P. Fouilloux and B. Moraweck, in: Growth and Properties of Metal Clusters, ed. J. Bourdon (Elsevier, Amsterdam, 1980) p. 421.

[22] R.W. Joyner and P. Meehan, Vacuum 33 (1983) 691

[23] J.A.A. van den Tillaart, B.F.M. Kuster and G.B. Marin, in: Catalytic Selective Oxidation, ACS Symposium Series 523, eds. S.T. Oyama and J.W. Hightower (American Chemical Society, Washington, 1993) p. 298.

[24] M. Boudart and G. Djéga-Mariadassou, Kinetics of Heterogeneous Catalytic Reactions (Princeton University Press, Princeton, 1984). 